\title{
Armas revolucionarias. Discusiones sobre la violencia en los grupos disidentes de Montoneros en los años setenta ${ }^{1}$
}

\author{
Revolutionary weapons. Discussions on violence in the dissident \\ groups of Montoneros in the 1970s
}

\author{
Daniela Slipak \\ Instituto de Altos Estudios Sociales; \\ Universidad Nacional de San Martín; \\ Consejo Nacional de Investigaciones Científicas y Técnicas (Argentina) \\ danielaslipak@hotmail.com
}

\begin{abstract}
Resumen
En este artículo examino los sentidos sobre la violencia que distintas disidencias grupales de Montoneros desplegaron durante la década del setenta. ¿Fue desestimada por los grupos que rompieron con la organización? ¿Qué enunciaron sobre la violencia revolucionaria y sus posibilidades en la coyuntura? ¿Cuáles fueron sus similitudes y distancias? Para dar respuesta a estos interrogantes, analizo un conjunto de documentos y publicaciones que los Montoneros Columna José Sabino Navarro de 1972, la Juventud Peronista Lealtad de 1974, el Peronismo Montonero Auténtico de 1979, y los Montoneros 17 de Octubre de 1980 publicaron en Argentina y en el exilio. Además, si bien no constituyó una disidencia grupal, tomaré las críticas de Rodolfo Walsh. Con ello, pretendo realizar tres aportes: a) contribuir a un área todavía vacante en la bibliografía académica, que es la de los grupos disidentes que Montoneros tuvo en distintos momentos de su derrotero; b) brindar elementos para restituir la diversidad de la militancia en los años setenta; y c) problematizar, desde una perspectiva teórico-política, el vínculo conceptual entre violencia y política en las identidades insurgentes de la época.
\end{abstract}

Palabras Clave

Violencia; Montoneros; disidencias; pueblo.

\footnotetext{
${ }^{1}$ Agradezco los comentarios, críticas y sugerencias de Sebastián R. Giménez, de las coordinadoras del dossier, y de los/las evaluadores/as del artículo a versiones preliminares de este texto.
}

Esta obra está sujeta a la Licencia Reconocimiento-NoComercial-CompartirIgual 4.0 Internacional de Creative Commons. http://creativecommons.org/licenses/by-nc-sa/4.0/ 


\title{
Daniela Slipak
}

\begin{abstract}
In this article, I examine the senses about violence that different group dissidents of Montoneros displayed during the seventies. Was it dismissed by the groups that broke with the organization? What did they say about revolutionary violence and its possibilities? Which were their similarities and distances? To answer these questions, I analyze a set of documents and publications that the Montoneros Columna José Sabino Navarro of 1972, the Juventud Peronista Lealtad of 1974, the Peronismo Montonero Auténtico of 1979, and the Montoneros 17 de octubre of 1980 published in Argentina and in exile. Besides the fact it was not part of a collective dissidence, I will take under consideration the criticism of Rodolfo Walsh. With this, I intend to make three contributions: a) contribute to an area still vacant in the academic bibliography, which is that of the dissident groups that Montoneros had at different moments of his course; b) provide elements to restore the diversity of the militancy in the seventies; and c) problematize, from a theoretical-political perspective, the conceptual link between violence and politics in the insurgent identities of the time.
\end{abstract}

\section{Keywords}

Violence; Montoneros; dissidences; people.

\section{Introducción}

En la bibliografía académica más clásica sobre los grupos insurgentes argentinos de los setenta -particularmente en la referida a la organización Montoneros- suele predominar una clave de lectura que ordena su derrotero bajo el esquema de dos etapas sucesivas: una política, en donde la violencia tuvo apoyo de los sectores populares y supuso alianzas con otros actores (así como trabajo en territorios, fábricas y universidades); y otra militarizada, en donde la violencia se ejerció bajo el horizonte bélico, se alejó de la política y se aisló de las tramas sociales. Es decir, una clave de inteligibilidad que traza el deslizamiento entre dos tipos de violencias, una "popular" y "revolucionaria" que respondía a la historia y la situación del país, y otra "militarista" despegada de su contexto político (Gillespie, 1987; Calveiro, 2005; Moyano, 1995; Ollier, 1998; Svampa, 2003). ${ }^{2}$

Quisiera rastrear en las páginas siguientes aquello que los actores enunciaron al respecto. Es decir, qué sentidos articularon en torno a su decisión por la violencia. En particular, pondré el foco en un conjunto de voces disidentes de Montoneros que fueron ignoradas, negadas o reprimidas por su órgano directivo, la Conducción Nacional, y que han sido sólo parcialmente abordadas por los estudios académicos. Más que adentrarme en la conformación y la dinámica que tuvieron dichos espacios en momentos y lugares disímiles, me interesa delimitar aquí sus argumentaciones en torno a la especificidad de la práctica armada. Esto supondrá atender, antes que

\footnotetext{
${ }^{2}$ Valga mencionar que esta clave de lectura que sustituye dos tipos de violencias se potencia en los acercamientos periodísticos o testimoniales (El Kadri y Rulli, 1984; Anzorena, 1998; Anguita y Caparrós, 2006; Grassi, 2015; etc.).
} 


\section{Armas revolucionarias. Discusiones sobre la violencia en los grupos disidentes de Montoneros en los años setenta}

a las características fácticas de las intervenciones violentas (sean robos, secuestros, asaltos de establecimientos o asesinatos), a las discusiones enhebradas sobre el tema. Siguiendo esta línea, me interesa problematizar la violencia no tanto en su carácter de instrumento (como un medio de obtención de determinados fines), sino remitirme al plano de los símbolos, concepciones e identidades articulados en torno de ella. ${ }^{3}$ Examinaré, entonces, las representaciones sobre la violencia que distintas disidencias grupales de Montoneros hicieron circular durante la década del setenta. ¿Fue desestimada por los espacios que se escindieron de la organización? ¿Qué enunciaron sobre la violencia revolucionaria y sus posibilidades en la coyuntura? ¿Cuáles fueron sus similitudes y distancias? Para dar respuesta a estos interrogantes, analizaré un conjunto de documentos y publicaciones que los Montoneros Columna José Sabino Navarro de 1972, la Juventud Peronista Lealtad de 1974, el Peronismo Montonero Auténtico de 1979, y los Montoneros 17 de Octubre de 1980 publicaron en Argentina y en el exilio. Además, si bien no constituyó una disidencia grupal, tomaré las críticas de Rodolfo Walsh. Con ello, pretendo realizar tres aportes: a) contribuir a un área todavía vacante en la bibliografía, que es la de los grupos disidentes que Montoneros tuvo en distintos momentos de su derrotero; b) brindar elementos para restituir la diversidad de la militancia en los años setenta; y c) problematizar, desde una perspectiva teóricopolítica, el vínculo conceptual entre violencia y política en las identidades insurgentes de la época. ${ }^{4}$

\section{Voces disidentes en Argentina}

La Columna José Sabino Navarro constituyó uno de los tempranos grupos que se distanciaron de la organización, antes de la apertura electoral que desembocó en el gobierno de Héctor Cámpora en mayo de 1973. A través de los vínculos trazados en la cárcel entre un conjunto de militantes, y con sostén en redes de Córdoba y Santa Fe, fueron la primera voz disidente con relativa circulación. Si, al principio, mediante

\footnotetext{
${ }^{3}$ En otro lugar, y anclado en la perspectiva de Hannah Arendt, he problematizado la reducción de la violencia a su dimensión instrumental (separada, pues, de los fines y proyectos a los que sirve), tratando de dar lugar a su dimensión simbólica, es decir, como práctica inescindible de los lazos de pertenencia, representaciones y símbolos (Slipak, 2019). En esta dirección se orienta el presente artículo. Sobre el concepto de identidad política, pueden verse los trabajos de Gerardo Aboy Carlés (paradigmáticamente, 2001).

4 Para completar el análisis de los grupos disidentes de Montoneros hasta su última operación político-militar, faltarían incluir a los Montoneros Columna de Recuperación Cooke-Pujadas de 1974 y a la Agrupación Eva Perón de 1980. Dejo dicha indagación para futuros trabajos. Debo aclarar que la categoría "disidencia" no es un término nativo sino analítico que me permite agrupar a aquellos espacios que se separaron de Montoneros en distintas circunstancias de su derrotero y que tuvieron una dinámica paralela, más allá de su brevedad o precariedad. Un análisis más completo de tres de ellos puede verse en Slipak (2018). Para sostener la breve descripción que realizo de cada disidencia, además de sus documentos internos y publicaciones, y de la bibliografía secundaria, utilizo entrevistas en profundidad que realicé a ex militantes, con los recaudos metodológicos correspondientes (Portelli, 1991 y 2017; Carnovale, 2007).
} 


\title{
Daniela Slipak
}

el llamado "Documento Verde", buscaron articularse como una autocrítica para permanecer en el ámbito montonero, con el tiempo se convirtieron en un espacio con dinámica propia. Además de un pequeño circuito armado, tuvieron presencia en fábricas, barrios y universidades. A través de la agrupación Peronismo Descamisado, desplegaron frentes barriales y sindicales en Córdoba. Entre sus militantes estuvieron Ignacio Vélez, Carlos Soratti, Luis Losada, Jorge Cottone, Antonio Riestra, Carlos Figueroa, José Fierro y Luis Rodeiro. Para sentar su posición entre los distintos grupos insurgentes y persuadir militantes, sostuvieron una permanente política de comunicación y prensa, con documentos y cuadernillos (muchos de ellos vieron la luz en las revistas Nuevo Hombre y Militancia Peronista para la Liberación) y con la edición de la revista Puro Pueblo (Venceremos) (Seminara, 2015; Rodeiro, 1996, 2006 y 2015; Inchauspe y Noguera, 2011 y 2015).

Las críticas que efectuaron a Montoneros se resumieron en las siguientes cuestiones: por un lado, se oponían a los intercambios de la cúpula montonera con otros sectores del Movimiento Peronista, fundamentalmente durante el proceso de apertura electoral y de conformación del Frente Justicialista de Liberación (es decir, impugnaban su movimientismo, para utilizar las categorías de la época); por el otro, reclamaron la falta de lo que consideraban era el trabajo político con los sectores populares. Advirtieron que la Conducción Nacional pretendía sustituirlos en el proceso revolucionario. Finalmente, sobre el punto que me interesa en estas páginas, afirmaron:

\begin{abstract}
"Los hechos focos que se propusieran como punto de partida de su tarea como pretendida vanguardia, ante la amplia recepción popular que motivó un triunfalismo sin análisis, pasaron a convertirse en concepción totalizadora de guerra, dando rienda suelta a nuestro 'foquismo', a nuestro 'aparatismo', a nuestro 'militarismo'. [...] Nosotros creemos que el objetivo del Ejército Popular no está puesto en cuestión, sino enmarcado en una estrategia de guerra popular prolongada que parte de abajo hacia arriba. [...] 0 sea, no se trata de abandonar los 'fierros', se trata de darles la orientación que las circunstancias históricas, nuestros objetivos políticos, nuestra estrategia de poder, determinan en esta concepción revolucionaria que abrazaremos, si somos capaces de autocriticarnos leyendo en la realidad la verdad histórica." ${ }^{5}$
\end{abstract}

Más que detenerme en las concepciones provenientes de la tradición marxista que esta disidencia articuló, quisiera subrayar que una de sus impugnaciones más importantes hacia la Conducción Nacional se orientó a los modos de la violencia. Argumentaban que la cúpula montonera la valoraba por demás, y que idealizaba la figura del militante armado. Según su perspectiva, las armas sólo debían ser aceptadas siempre y cuando se conjugaran con una militancia "de superficie", "desde las bases, desde la inmersión en ellas"6. Si no, se caía en "foquismo", "militarismo", "aparatismo". Siguiendo esta línea, criticaron la declaración de pase

\footnotetext{
${ }^{5}$ Documento Verde, jul. 1972, pp. 38, 44 y 45.

${ }^{6}$ Ibíd, p. 44.
} 


\section{Armas revolucionarias. Discusiones sobre la violencia en los grupos disidentes de Montoneros en los años setenta}

a la clandestinidad anunciada a comienzos de septiembre de 1974 durante el gobierno de María Estela Martínez de Perón.

Para esta disidencia, debía repensarse de otra manera la articulación entre política y violencia, así como los elementos de la identidad militante. Pero ello no significaba descartar la violencia como modo de intervención pública ni la gramática bélica como horizonte de sentido de la práctica política; tampoco en tiempos de los gobiernos constitucionales que siguieron (de hecho, como mencioné, "los sabino" mantuvieron un circuito armado reducido, aunque supeditado a las decisiones de los dirigentes políticos). De lo que se trataba, antes bien, era de pensar esa violencia en articulación con el trabajo barrial y sindical.7 Sólo así podría desplegarse el camino a la mentada revolución, orientándola en la dirección de dos sujetos de permanente evocación aunque de difícil identificación en la coyuntura: el "pueblo y la clase obrera".

Como puede verse, la Columna José Sabino Navarro anticipó así el tono de las discusiones que vendrían en los años sucesivos, y lo hizo bastante antes del proceso de militarización usualmente identificado para mediados de la década del setenta. Más allá de que las acciones armadas crecieron en ese entonces, en un contexto de elevada represión legal e ilegal por parte de un entramado estatal y paraestatal, lo cierto es que el debate respecto del exceso de lo militar por sobre lo político (que no implicaba el abandono de la idea de violencia ni de la de guerra) ya había sido planteado tiempo atrás. Desde luego, la Conducción Nacional nunca debatió las críticas de "los sabino", ni cuando pretendían pertenecer al ámbito montonero ni cuando se consolidaron como un grupo alternativo. Lejos de ello, los mandó a estudiar el "pensamiento nacional", primero, y los acusó de “contrarrevolucionarios", después (Rodeiro, 1996, pp. 96-97) ${ }^{8}$.

No muchos meses más tarde, durante el último gobierno de Juan Domingo Perón, se produjo otra ruptura al interior de las redes montoneras, de modo menos orgánico aunque con mayores implicancias cuantitativas y cualitativas. En ese entonces, Montoneros se había convertido en una cuantiosa organización político-militar, con redes en universidades, colegios, barrios, fábricas, y villas de emergencia, a las que

\footnotetext{
7 Esquemas similares sobre la violencia aparecieron en notas posteriores de la disidencia. A principios de 1974, sentenciaron: "Sabíamos que las elecciones [del 11 de marzo de 1973] no eran el 'abracadabra' de nuestra felicidad. [...] [Nuestro camino] pasa por la construcción del ejercito popular desde las bases", Ante la confusión, Militancia, n. 32, 24/01/74, p. 33. A su vez, una nota de Puro Pueblo Venceremos que comentaba dos operaciones militares del Ejército Revolucionario del Pueblo en Córdoba y Catamarca cometidas en agosto de 1974 durante el gobierno de María Estela Martínez de Perón (tras la última, el Ejército asesinó a 16 guerrilleros, hecho que se conoce como la "masacre de capilla del Rosario") advertía: "Villa María y Catamarca -más allá del éxito del primero y la derrota del segundo- pone nuevamente en cuestión el análisis de la etapa por la que atravesamos y señala para nosotros el error de una política 'militarista' que no tiene en cuenta en su estrategia el proceso de las masas [...] Sabemos que habrá guerra, que la clase obrera y el pueblo no serán poder definitivo sin violencia, sin enfrentamiento, sin ejército popular. [...Pero] sólo la clase obrera y el pueblo organizado garantizará la larga marcha al Socialismo por la que dieron la vida los compañeros muertos", Los fusilados en Catamarca y el tiempo de la guerra, Puro Pueblo Venceremos, n. 4, 2da quin. agos. 1974, p. 29.

${ }^{8}$ El peronista lucha por la liberación, n. 5, 21/05/74, p. 6
} 


\section{Daniela Slipak}

se sumaba el núcleo militar. En el marco de las crecientes tensiones con Perón, desde inicios hasta mediados de 1974, distintas columnas, unidades básicas e integrantes del circuito armado y de la llamada Tendencia Revolucionaria (de las Juventudes Peronistas Regionales, de la Juventud Trabajadora Peronista, de la Juventud Universitaria Peronista, de la Unión de Estudiantes Secundarios, del Movimiento Villero Peronista) decidieron desligarse sucesivamente de la Conducción Nacional. Así se conformaron los Montoneros Soldados de Perón, la Juventud Peronista Lealtad, la Unión de Estudiantes Secundarios Lealtad, la Juventud Universitaria Lealtad, y la Juventud Trabajadora Peronista Lealtad, con redes en Capital Federal y provincia de Buenos Aires, en Santa Fe, en Corrientes, en Neuquén y en algunas localidades del sur del país. Entre sus dirigentes estuvieron Eduardo Moreno, Alejandro Peyrou, Enrique Padilla, Nicolás Giménez, Norberto Ivancich, Ernesto Villanueva, Jorge Obeid, Patricio Jeanmaire, los sacerdotes Jorge Galli y Jorge Goñi. Además, existió una Coordinadora Provisoria de la JP Lealtad integrada por Horacio González, Edmundo González, José R. Canalls, Ricardo Gómez, Mario Maidovani, Norberto Ivancich, Mario Cisneros, Enrique H. Vallejos, Roberto Hyon y Víctor Espinosa. Conjugaban, al igual que su "organización madre", espacios armados con ámbitos legales (Salcedo, 2011; Pozzoni, 2017; Montero, 2009; Peyrou, 2010; Duzdevich, Raffoul y Beltramini, 2015).

Así como lo había hecho la disidencia anterior, argumentaron el porqué de su ruptura en diversos comunicados y declaraciones. También existió una revista, Movimiento para la Reconstrucción y Liberación Nacional, pero en este caso no fue orgánica, sino que buscaba difundir los debates que se sucedían en estos sectores no alineados con la cúpula montonera. ${ }^{9}$ Las explicaciones de la escisión anidaron en las siguientes cuestiones: por un lado, y a diferencia de la crítica de "los sabino", se impugnaba la falta de vínculos con el resto de los sectores del Movimiento Peronista, y, sobre todo, el enfrentamiento explícito con Perón (es decir, se demandaba no menos sino más movimientismo y obediencia a las directivas del presidente); por otro lado, y acá sí en sintonía con la disidencia precedente, se cuestionaba la falta de representatividad de la cúpula montonera respecto de las reivindicaciones de los sectores populares; finalmente, acusaban a la Conducción de desviarse de la doctrina peronista y acercarse a los esquemas del marxismo-leninismo (sobre todo, a partir de la fusión formal en octubre de 1973 con las Fuerzas Armadas Revolucionarias y la circulación del documento que se conoce como "Mamotreto"). Sobre el punto que me interesa, decían:

“Mientras en la etapa anterior las acciones de desgaste contra el régimen
señalaban la necesidad de dar prioridad a la formación de cuadros capaces de
dar esa batalla, en la actual etapa de gobierno las formas de organización
político-militar deben variar radicalmente. En esta etapa aparece como

\footnotetext{
${ }^{9}$ Es de mencionar que también la mayor parte del staff de la revista Envido, cuyo último número fue de noviembre de 1973, poco antes de la formalización de la ruptura, también adhirió a la disidencia. Participó meses más tarde de Aluvión, Lealtad y participación popular, publicación de un único número de julio de 1974, que se hizo eco de las ideas generales de "los leales" (Pozzoni, 2017).
} 


\title{
Armas revolucionarias. Discusiones sobre la violencia en los grupos disidentes de Montoneros en los años setenta
}

prioritaria la consolidación de las fuerzas propias a través de una política de expansión hacia las masas, tendiendo a amplificar el campo de organización del pueblo. La juventud debe 'velar las armas' y centrar su esfuerzo en la ampliación del campo organizativo del pueblo." 10

\begin{abstract}
“...hubo en nuestra patria una violencia justa que -desde los caños obreros de la resistencia a los más altos niveles de organización popular- se insertaba en la estrategia de nuestro conductor por recuperar el poder. Es el contexto lo que califica a una y otra forma de violencia; es el proyecto político al que objetivamente sirven lo que las diferencia de contrarrevolucionaria y revolucionaria. [...] Ninguna forma de violencia podrá pretenderse 'revolucionaria' cuando se dirige contra las estructuras de un gobierno y el desarrollo de un proceso que cuenta con el voto masivo del pueblo. [...] No hay violencia revolucionaria si ésta no se inserta a la propuesta política de las masas." 11
\end{abstract}

La disidencia de "los leales" fue una de las rupturas que más rechazó la violencia como modo de intervenir en la coyuntura, y acusó a la Conducción Nacional de "matonismo" y "fierrerismo".12 Siguiendo esta línea, cuestionó el asesinato del secretario general de la CGT, José Ignacio Rucci, de septiembre de 1973 (por cierto, una de las operaciones más condenadas dentro del derrotero de la organización, ya sea por críticos o simpatizantes). ${ }^{13}$ Además, según algunos testimonios, un sector de la disidencia realizó, a pedido de Perón, una voladura simbólica de algunas armas en la zona del Delta escenificando su abandono (Salcedo, 2011, p. 270). No obstante, como se ve en sus documentos y como lo patenta el mantenimiento de un circuito militar dentro de sus tramas (Pozzoni, 2017), la disidencia no fue tan lineal. Adujo que la violencia ciudadana sí había sido "justa” desde 1955 hasta la apertura electoral de 1973 en el marco de "la estrategia de [Perón] por recuperar el poder", y que, en cambio, se convertía en "contrarrevolucionaria" cuando se ejercía en el marco o contra de un "gobierno popular". ${ }^{14}$ Con este criterio, apoyó a los gobiernos del periodo y cuestionó las intervenciones de la izquierda armada, así como también la de los grupos paraestatales que en ese momento intensificaban su accionar. Al

\footnotetext{
10 Respuesta de Montoneros de Moreno al Mamotreto, feb./mar. 1974.

11 Profundizar la revolución, Movimiento, n. 8, 2da quin. agos. 1974, p. 8, énfasis original.

12 Movimiento, n. 6, 2da quin. jul. 1974, p. 6.

13 Es recién en su revista clandestina Evita Montonera que la organización asumió la autoría del hecho. Justicia popular, n. 5, jun.-jul. 1975, p. 18.

14 Varias notas de Movimiento sostuvieron dicho argumento: "Para quienes creímos durante 18 años que la lucha violenta fue una herramienta indispensable -aunque para nada la única- hacia la liberación, nos resulta un error particularmente peligroso, que hoy muchos siguen cometiendo, el seguir manejando esa misma herramienta para presionar, cuando no lisa y llanamente para atacar al gobierno popular. [...] Hoy las masas populares no encuentran motivos para apelar a la violencia y quienes la ejercen no sólo no las representan sino que promueven un distanciamiento del pueblo respecto de la acción política cotidiana", Guerra al imperialismo, n. 2, 2da quin. may. 1974, p.1, énfasis original. También: "Producido el triunfo popular del 11 de marzo de 1973, vuelto al país el indiscutido líder popular, el General Perón, concretado su retorno al Gobierno el 23 de setiembre del año pasado, toda violencia institucionalizada -parapolicial o falsamente representativa del sentir popular- impide profundizar el proceso de Participación Popular y, por tanto, es objetivamente contrarrevolucionaria", La violencia en la historia, n. 2, 2da quin. may. 1974, p. 31.
} 


\section{Daniela Slipak}

hacerlo, sostuvo que la "unidad nacional" se encontraba amenazada por dos violencias, una "subversiva" proveniente de los grupos insurgentes, y otra impulsada por la "ultraderecha y parapolicial". ${ }^{15}$ Coadyuvó así a una narración bipolar sobre la violencia que circuló antes -y no sólo después, como tiende a creerse al impugnar la teoría de los dos demonios- de la instauración del terrorismo estatal, y que, al tiempo que equiparaba dichos polos, desconocía sus múltiples vasos comunicantes con el resto de la sociedad y del gobierno de ese entonces y de tiempos pasados (Franco, 2012 y 2015; Slipak, 2015).

Pero lo que quisiera resaltar aquí es otra cosa: si bien la Lealtad se opuso de modo enfático a la violencia ejercida por los grupos insurgentes desde la asunción de Héctor Cámpora en mayo de 1973, lo cierto es que en dicho rechazo convivían de modo imbricado dos criterios. El primero desechaba la violencia como práctica de intervención durante cualquier gobierno constitucional, sea del signo partidario que sea; el segundo la desechaba como opción durante un gobierno peronista o "popular". Uno respondía a la formalidad jurídica que sanciona el monopolio de la violencia estatal por parte de un gobierno constitucional; el otro a un tipo de legitimidad sustantiva respecto de quién y dónde está el "pueblo”. Uno proponía un criterio novedoso en la historia de las disidencias montoneras; el otro se acercaba un poco más, aunque sin haberse producido mucho diálogo, a las argumentaciones de "los sabino", quienes demandaban la articulación de la violencia con la organización de los sectores populares.

Por su parte, la Conducción Nacional desestimó una vez más las críticas. Según los testimonios, al producirse la ruptura de la Lealtad, la organización amenazó con sanciones que incluían la muerte. Sin embargo, no se conocen asesinatos de leales bajo imputación de disidencia, aunque sí numerosas amenazas de "ajusticiamiento" acompañadas con acusaciones de "traición". También encierros en "cárceles del pueblo" con la exigencia de realizar autocríticas, o "traslados" a otros lugares del país (Duzdevich, Raffoul y Beltramini, 2015, p. 225; Salcedo, 2011; entrevistas realizadas por la autora con fechas 19/5/2011, 2/6/2011, 15/7/2011, у 19/4/2012). ${ }^{16}$ En todo caso, más allá de la respuesta de la Conducción Nacional, lo cierto es que esta última disidencia previa a su exilio duró poco en el escenario político, no mucho más de 1974, tanto por la creciente represión estatal y paraestatal así como por el carácter desarticulado y descentralizado de la experiencia.

\footnotetext{
${ }^{15}$ Movimiento, n. 10, 2da quin. sept. 1974, pp. 1 y 7.

16 Para ese entonces, se encontraban vigentes las "Disposiciones sobre la Justicia Penal Revolucionaria", cuya importancia radicó en ser un marco simbólico y normativo, más que en su aplicación efectiva (Lenci, 2008). Sancionaban con "fusilamiento" la "deserción en combate" y la "traición" (entendida sin demasiada precisión como "servir conscientemente al enemigo"), aunque no la "deserción de la Organización" que no tenía prevista pena explícita. Las "Disposiciones" se encuentran en la Comisión Provincial por la Memoria, situada en La Plata, Archivo DIPBA, Mesa D (s), Carpeta Varios, Legajo n. 581, 16 fol.
} 


\section{Armas revolucionarias. Discusiones sobre la violencia en los grupos disidentes de Montoneros en los años setenta}

\section{Voces disidentes en el exilio}

Dada la intensidad represiva que estaba adquiriendo el terrorismo estatal, a fines de 1976 el Consejo Nacional de Montoneros decidió e implementó la salida del país de los cuadros de mayor jerarquía. Esto se sumaba, desde luego, a los exilios que, a título individual, habían realizado algunos militantes desde 1974, momento en que había empezado a recrudecer la represión legal e ilegal (Franco, 2008 y 2012; Yanquelevich, 2010; Jensen, 2010; Jensen y Lastra, 2014). Desde mediados de 1976 hasta comienzos de 1977, Rodolfo Walsh, oficial del sector de Informaciones y director de la Agencia Clandestina de Noticias, apuntó una serie de escritos cuyo tono contrastaba con el de los boletines oficiales. Aunque no provocaron ninguna ruptura en particular, vale la pena detenerse en ellos porque enhebran los esquemas propuestos por las disidencias precedentes con los que desplegarían las del exilio. Walsh impugnó el "militarismo" de la Conducción, su ausencia de trabajo político, su alejamiento respecto de las "masas", su negación de la realidad, y su intento por imponerle esquemas propios. A su vez, marcó los inconvenientes de las transformaciones organizacionales propuestas en los últimos meses, y criticó la pretensión de abandonar la tradición del peronismo y de reemplazarla por el montonerismo. ${ }^{17}$ Advirtió, además, los problemas de la "personalización" en torno al líder de la Conducción Nacional, Mario Firmenich, y la "desconfianza” y el "malestar" que todo esto generaba en la militancia. Finalmente, sentenció que en 1976 la organización había sufrido una "derrota militar que amenazaba convertirse en exterminio". 18

Si bien las críticas fueron múltiples y contundentes, lo cierto es que los sentidos sobre la violencia presentaron un vaivén que no era tan novedoso. Walsh reclamaba el abandono de la "ofensiva" y de una estrategia de guerra contra la dictadura militar (que, en verdad, en la jerga montonera de ese entonces, asumía el nombre de etapa de "resistencia" dentro de la "defensiva estratégica") ${ }^{19}$ y afirmaba que era necesaria una declaración de "tregua" y de "paz", y el reconocimiento de la "derrota militar". Sin embargo, aducía que, tras su probable rechazo por parte de las Fuerzas Armadas, debía desplegarse una fase de "resistencia" (entendida como una "forma de guerra diluida") que cuestionara "los efectos inmediatos del orden social, incluso por la

\footnotetext{
17 Desde 1975 hasta 1977, la antigua organización político-militar (que tenía su Conducción Nacional, el Consejo Nacional, el Área Federal, las columnas, las regionales, las unidades básicas de combate y las unidades básicas revolucionarias, además de las agrupaciones de superficie) se convirtió en el Ejército Montonero, el Partido Montonero, y el Movimiento Peronista Montonero (que al inicio pensaba nominarse Movimiento Montonero, dando por agotado el peronismo). Al respecto puede consultarse la siguiente prensa de la organización: Evita Montonera, n. 8, oct. 1975, pp. 25-26; n. 12, feb.-mar. 1976, pp. 26-27; n. 14, oct. 1976, pp. 13-22; y El Montonero, n. 11, 24/04/76, pp. 9-11.

18 Los papeles de Walsh, publicados en Cuadernos del Peronismo Montonero Auténtico, oct. 1979, p. 14. Los escritos de Walsh tienen fechas de 27/08/76, 23/11/76, 02/01/77 y 05/01/77.

${ }^{19}$ Evita Montonera, n. 12, feb.-mar. 1976, p. 6.
} 


\section{Daniela Slipak}

violencia", y que utilizara "las armas solamente en defensa de la vida o la libertad". Para él, la "resistencia" incluía acciones militares pero "ligada[s] en forma directa inconfundible con un interés inmediato de las masas". Y agregaba que esta etapa sería sólo hasta que "aparezca una nueva posibilidad de apostar al poder", es decir, una puerta para volver a declarar la guerra. ${ }^{20}$ Por tanto, podría decirse que, en continuidad con "los sabino" y "los leales", aunque en otra instancia del derrotero montonero así como del panorama del país, resurgía el argumento respecto de los inconvenientes del exceso de lo militar y de la violencia por sobre lo político, pero sin desarticular del todo la creencia en las armas y el horizonte bélico. ${ }^{21}$

Aunque la Conducción Nacional distribuyó en el exilio la conocida carta de denuncia de Walsh a la dictadura militar, ${ }^{22}$ obvió toda esta documentación. Fue recién dada a conocer por una disidencia tardía de Montoneros, el Peronismo Montonero Auténtico de 1979, que se separó justo antes de implementarse la primera fase de la última operación político-militar de envergadura, la Contraofensiva Estratégica (Confino, 2018). En ese entonces, la organización ya tenía buena parte de su militancia detenida-desaparecida o asesinada por el terrorismo estatal. Esta escisión fue impulsada por un conjunto de militantes que habían tenido tensiones con la Conducción Nacional mientras formaban parte de la Columna Norte en los inicios de la dictadura (Sadi, 2009; Caballero y Larraquy, 2000), a los que se sumaron exiliados disconformes con el diagnóstico que la cúpula proponía de la coyuntura argentina. Amparada en el último código disciplinario (el "Código de Justicia Penal Revolucionario"), en marzo de 1979 la Conducción Nacional acusó a los disidentes de "deserción", "insubordinación", "conspiración” y "defraudación”, y solicitó "la aplicación del máximo rigor que corresponda a la imposición de las penas por los delitos de que son acusados". ${ }^{23}$ La pena máxima no se cumplió pero, desde luego, condicionó el transitar de los disidentes durante un tiempo. No obstante, el 29 de mayo de 1979, se hizo la presentación de la Mesa Promotora del flamante Peronismo Montonero Auténtico en París. Entre sus integrantes estuvieron Rodolfo Galimberti, Juan Gelman, Pablo y Miguel Fernández Long, Patricia y Julieta Bullrich, Marcelo Langieri, Arnaldo Lizaso, Héctor Mauriño, Raúl Magario, Victoria Vaccaro, Claudia Genoud y Silvia Di Fiorio. Efectuó luego operativos de retorno a la Argentina para contactar militantes aislados, realizar propaganda y trazar redes. Según los testimonios, tuvo representantes en Suecia, Suiza, México, Francia y España

\footnotetext{
${ }^{20}$ Los Papeles de Walsh en Cuadernos del Peronismo Montonero Auténtico, oct. 1979, pp. 15-16 y 19.

21 "Es un grave error olvidar que ésta es una lucha política y que para la construcción organizativa las operaciones militares deben servirnos ante todo para hacer política y no para construir un ejército cuando todavía no tenemos ganada la representatividad de nuestro pueblo [...Se trata de] ligar la resistencia en forma absoluta a la política de masas, privilegiando en primer término las estructuras militares defensivas (documentación, información, comunicaciones) y las estructuras políticas defensivas (propaganda, agitación, prensa clandestina y descentralizada en lo interno, prensa internacional", ibíd., pp. 9 y 14.

${ }^{22}$ Lettre ouverte d'un écrivain à la Junte militaire d'Argentine, Mouvement Peroniste Montonero, sin fecha.

${ }^{23}$ Sobre la deserción de cinco militantes del Partido y cuatro milicianos en el exterior, Partido Montonero, 1979.
} 


\title{
Armas revolucionarias. Discusiones sobre la violencia en los grupos disidentes de Montoneros en los años setenta
}

(entrevistas realizadas por la autora con fechas 13/10/2016, 1/11/2016 y $22 / 11 / 2016)$. Al igual que el resto de las disidencias, se ocupó de visibilizar las razones de la ruptura en diversos documentos y notas que aparecieron en medios de comunicación europeos. Además, editó artesanalmente los primeros números de la revista Jotapé. ${ }^{24}$ Finalmente, como mencioné antes, dieron a conocer en octubre de 1979 "Los papeles de Walsh" para romper el silencio de la cúpula dirigente (Slipak, 2018).

Aunque esta ruptura sucedió a partir de la Contraofensiva, lo cierto es que los argumentos fueron mucho más allá. Las impugnaciones del Peronismo Montonero Auténtico se orientaron a las características y las decisiones tomadas por la Conducción Nacional desde los inicios del derrotero montonero. En su documento programático de junio de 1979, "Reflexiones para la construcción de una alternativa peronista montonera auténtica”, hicieron referencia a la ausencia de participación y discusión colectiva en la toma de decisiones, al autoritarismo de la cúpula (que la llevaba a sostener una "estructura monárquica"), a su triunfalismo irresponsable, a su sectarismo, a su desestimación de las masas, y a su falta de apoyo a los diversos militantes en los momentos iniciales de la dictadura. ${ }^{25}$ Sobre el problema que me interesa, sostuvieron:

\begin{abstract}
"En lo que hace al problema de la violencia como instrumento de una estrategia revolucionaria, es decir, a la cuestión concreta de su sistematización como un camino para la toma del poder, nosotros creemos que toda propuesta seria debe comenzar por estudiar las distintas etapas por las que atravesó la concepción de la organización de la violencia popular en los últimos veinte años en la Argentina [...] Es indudable que la resistencia -cuya potencia deviene de que expresa la voluntad de millones-, no puede reducirse al infantil jugar a los soldados de un puñado, sino que exige oponer a la dictadura todos los recursos de la lucha de masas, que no elude el crecimiento de los niveles de violencia que éstas desarrollan, y que pueden, y deben, ir asumiendo formas organizadas, pero nunca al revés. Las formas organizadas no pueden preceder al crecimiento de los niveles de violencia que desarrolla la resistencia de las masas. [...] El ejército popular, de existir, sería, en consecuencia, la última forma organizativa en aparecer. [...] [L]a 'conducción' de la OPM no sostiene actualmente un foquismo ingenuo, sino malintencionado. [...] Nosotros afirmamos que es menester confiar en el desarrollo de la lucha de masas, desde el seno de ellas y en la acción con ellas, todo; y, desde luego, la legítima violencia resistente. [...] [Sobre el gobierno de Martínez de Perón] nosotros nos convertimos en opositores armados de un gobierno que era la sucesión constitucional del que habían votado esos mismos millones. [...E]l eje no debía haber sido la guerra, la lucha armada, porque esta diluía, definitivamente, la única posibilidad de aclarar el enfrentamiento de cara a las masas logrando así su participación."26
\end{abstract}

\footnotetext{
${ }^{24}$ Según Bernetti y Giardinelli (2014), el grupo editó posteriormente la publicación Revolución Peronista.

${ }^{25}$ Reflexiones para la construcción de una alternativa peronista montonera auténtica, jun. 1979, p. 22.

${ }^{26}$ Ibíd, pp. 13-15 y 20.
} 


\section{Daniela Slipak}

Aunque enmarcado en la situación del terrorismo estatal y del exilio, no podría afirmarse que las argumentaciones del Peronismo Montonero Auténtico eran disruptivas. Antes bien, restituían buena parte de los debates precedentes sobre las características y las posibilidades de la violencia insurgente. Al igual que en el resto de las disidencias, no se desestimaba su práctica, sobre todo en el marco de un gobierno de facto. A la vez, de forma más tenue pero en sintonía con la Juventud Peronista Lealtad, se marcaban las limitaciones de su desarrollo en el contexto de un gobierno constitucional. Asimismo, y a pesar de los cuestionamientos al "militarismo", no se desarticulaba del todo el horizonte bélico como marco para la acción política. El problema de la violencia, en todo caso, radicaba en despegarla del trabajo de organización de los sectores populares. Es decir, su sentido aparecía otra vez atado a la idea del "pueblo", y a la repetida dicotomía entre la "violencia popular" y la "violencia foquista". La disidencia buscaba así continuar la "resistencia" (categoría a esa altura abandonada por la Conducción Nacional) y corregir las dificultades del montonerismo con la presencia de las "masas".

Con el paso de los meses, las redes del Peronismo Montonero Auténtico fueron desarticulándose. Sin embargo, varios de sus esquemas interpretativos fueron reproducidos por el grupo disidente posterior, el último antes del cese definitivo de la "lucha armada" por parte de la Conducción Nacional. Los Montoneros 17 de octubre se separaron en el marco de los debates posteriores a la primera fase de la Contraofensiva, y debido a las intenciones de la cúpula de iniciar una segunda. A diferencia de la ruptura precedente signada por amenazas de muerte, en este caso ocurrió sin enfrentamientos frontales, luego de una reunión consensuada en la ciudad de Managua en Nicaragua (Bonasso, 2000). A fines de marzo de 1980, constituyeron su Consejo Provisorio, y en abril hicieron su presentación pública en México. Entre sus integrantes estuvieron Miguel Bonasso, Daniel Vaca Narvaja, Ernesto Jauretche, Susana Sanz, Jaime Dri, Pablo Ramos, Julio Rodríguez Anido, Pedro Orgambide, Sylvia Bermann, Eduardo Astiz, René Chavez, Gerardo Bavio y Olimpia Díaz. Se trataba del conjunto de militantes con el rango de tenientes que habían escrito a fines de 1979 el llamado "Documento de Madrid" (que, a diferencia de cualquier otra declaración crítica a lo largo de la historia montonera, había sido incluida y debatida en un boletín oficial de la organización) ${ }^{27}$, a los que se sumaron otros militantes disconformes. Algunos pocos habían retornado a la Argentina en la primera fase de la Contraofensiva (Confino, 2019a); otros volvían de colaborar con el Frente Sandinista de Liberación Nacional como parte de las proyecciones internacionalistas que Montoneros había implementado desde la Secretaría de Relaciones Exteriores (Cortina Orero, 2017). Además del documento mencionado, esta voz disidente dio a conocer sus pautas programáticas en abril de 1980. Finalmente, aunque el espacio no perduró muchos meses ni tuvo gravitación en la escena argentina, visibilizó su perspectiva mediante el relanzamiento de la revista

27 Documento de Madrid. Ante la crisis del Partido. Reflexiones críticas y una propuesta de superación, en el Boletín Interno n. 13, Partido Montonero, feb. 1980. 


\title{
Armas revolucionarias. Discusiones sobre la violencia en los grupos disidentes de Montoneros en los años setenta
}

Noticias, que anteriormente representaba al Movimiento Peronista Montonero. Ahora se convertía en el boletín de prensa de Montoneros 17 de Octubre. ${ }^{28}$ La nueva disidencia impugnó la evaluación que se estaba haciendo de la primera etapa de la Contraofensiva. Mucho más generalmente, cuestionó el exitismo y el triunfalismo de la Conducción, y la falta de participación colectiva en la toma de decisiones (ejemplificada con el rechazo a la demanda de realizar un congreso partidario, solicitado aproximadamente desde fines de 1974 en diversos círculos militantes). Además, sobre los modos implementados o proyectados de la violencia, sostuvieron:

\begin{abstract}
“[E]stamos plenamente de acuerdo [con la CN] en cuanto a que la insurrección armada de masas es el camino para la toma del poder.[...Pero] la concepción militarista llevó a despreciar la posibilidad reclamada por numerosos compañeros de los grupos de trabajo en el exterior: ir a la Argentina a hacer política. [...] Hay que preparar las fuerzas militares para aplicar -cuando la realidad lo aconseje- los golpes que efectivamente pueden desestabilizar el frente interno del enemigo. Adecuar los ataques al centro de gravedad del enemigo al desarrollo de la lucha de masas, y procurar que la violencia se vaya masificando mediante la proliferación de pequeñas acciones." ${ }^{29}$
\end{abstract}

"Pretendimos vanamente la masificación de la lucha armada a partir de presupuestos militaristas y vanguardistas, que nos fueron aislando de las masas. [...] Así como en 1973 los peronistas nos unimos en torno a la conducción de Perón y las pautas programáticas que el Pueblo plebiscitó en las urnas, hoy debemos unirnos en torno a un nuevo programa, en un proceso en el cual la clase trabajadora será su columna vertebral y conducción. Esto también reclama una estrategia para la toma del poder y el desarrollo en el seno del movimiento de masas de un partido revolucionario. [...] Un partido capaz de conducir una insurrección armada de masas; cuyo proyecto estratégico esté orientado a transformar nuestra sociedad, poniendo los medios de producción en manos de los trabajadores, tornando cierta y plena la justicia social, y profundizando la vida democrática a través de la lucha de los organismos de masas. [...D]ebemos construir una propuesta democrática que pueda ser asumida por el conjunto de sectores nacionales y populares, unidos en un Frente Cívico de Oposición. [...] Es necesario, pues, encauzar esa capacidad de lucha que se manifestó en la Resistencia a través de la huelga, el sabotaje, el trabajo 'a tristeza' y también instrumentando la violencia de 'los de abajo' contra la de los opresores [...] Debemos contribuir a cambiar el concepto de 'guerra' por el de 'rebeldía popular'." 30

\footnotetext{
${ }^{28}$ Es de mencionar que desde fines de 1973 a mediados de 1974 se había editado bajo el mismo título (aunque con el agregado "sobre todo lo que pasa en el mundo") un diario vinculado al sector de prensa del Área Federal de la organización político-militar Montoneros, que pretendía competir con los medios gráficos de tirada masiva. Su director fue Miguel Bonasso (Esquivada, 2009). Por otra parte, según Bernetti y Giardinelli (2014), un sector que provenía de esta disidencia publicó irregularmente Lucha Peronista.

29 Documento de Madrid. Ante la crisis del Partido. Reflexiones críticas y una propuesta de superación, en Boletín Interno n. 13, feb. 1980, pp. 2, 5, 11, énfasis original.

${ }^{30}$ Sin título, abr. 1980, pp. 3, 6, 8 y 11.
} 
Montoneros 17 de Octubre acusó a la Conducción Nacional de "militarista" y de "vanguardista", y adujo que sobrevaloraba la "lucha armada". Propuso reemplazar la categoría de "guerra" por la de "rebeldía popular". Y reclamó la necesidad de reunificar el peronismo y de construir, con otros espacios políticos, un Frente Cívico de Oposición de carácter "democrático" para enfrentar a la dictadura. Pero nada de ello la llevó a desestimar la violencia. Sostenía, en todo caso, que era necesario desplegarla y multiplicarla con "las masas", construir un "partido revolucionario" que las conduzca, y establecer alianzas con otros actores políticos. Al final del documento programático, además, reivindicaba la experiencia insurgente nicaragüense recientemente triunfante así como la salvadoreña. Y no olvidaba firmar, tal como sus integrantes debían hacerlo hace años, con la leyenda "patria o muerte". El problema para esta disidencia tardía, por tanto, no era tanto la violencia como práctica de intervención en la coyuntura, sino su desarticulación de los sectores "populares". Incluso, el "Documento de Madrid", escrito tan solo cuatro meses antes que las pautas programáticas, acordaba, a pesar de todas las críticas, con las líneas generales de la Contraofensiva y le reconocía sus "efectos positivos". Hernán Confino (2019a) sitúa los documentos de Montoneros 17 de Octubre en el marco más general de la experiencia exiliar, atravesada por el desplazamiento de las coordenadas revolucionarias hacia el horizonte liberal-democrático (articulado en torno al respeto por los derechos humanos y por la vida individual, la asunción de la derrota de los proyectos revolucionarios, y la creencia en la democracia como régimen político; Yankelevich, 2010; Jensen, 2007 y 2010; Franco, 2008; y Gago, 2012). Al respecto, el autor pone el foco en el abandono de la idea de "guerra" y en su reemplazo por la de "rebeldía popular" que esta disidencia expuso en sus pautas programáticas, y en su pretensión de desplegar alianzas políticas contra la dictadura. Además, si bien no aparece en los fragmentos que cité, advierte que este grupo llamó la atención sobre un punto invisible o irrelevante desde el imaginario de la Conducción Nacional, a saber, la "dolorosa" e "impresionante" pérdida de cuadros durante la implementación de la Contraofensiva. ${ }^{31}$ Ahora bien, sin discutir la importancia política de la experiencia exiliar como espacio de constitución de nuevas representaciones y percepciones (cuyo síntoma más evidente podrían ser las señaladas incomodidades frente a la ética sacrificial), ${ }^{32}$ creo que la trama de las

\footnotetext{
${ }^{31}$ Sobre las muertes de militantes que había implicado la Contraofensiva -pero no sobre las muertes de quienes eran considerados "enemigos", que sí había puesto en escena Héctor Schmucler al preguntar “¿Los derechos humanos son válidos para unos y no para otros?”, Controversia, n. 1, oct. 1979, p. 3-, decían: "Esta pérdida tremenda y simultánea que comprende a nivel dirigente a un cro. de la Conducción Nacional y siete cuadros del Comité Central tiene, además de las obvias secuelas organizativas, una consecuencia muy grave para la política de masas. [...] Visto numéricamente es impresionante pero no da cuenta de las calidades perdidas. [...Una] serie dolorosa de caídas", Documento de Madrid, Boletín Interno n. 13, feb. 1980, pp. 7 y 9.

32 Además, para complejizar el cuadro en relación a las representaciones construidas en el exilio, considero que sería necesario indagar el impacto que tuvo el triunfo sandinista en Nicaragua, tanto en las percepciones de los disidentes como en las de los que permanecieron en la organización (de hecho, como mencioné, Montoneros 17 de octubre reivindicó dicha victoria en sus pautas programáticas; también lo hizo la Conducción Nacional en el Boletín Interno n. 13, feb. 1980, sosteniendo que la estrategia a seguir era la "insurrección popular armada" y ya no la "guerra
} 


\section{Armas revolucionarias. Discusiones sobre la violencia en los grupos disidentes de Montoneros en los años setenta}

disidencias precedentes permite sumar otra lectura para comprender los documentos de Montoneros 17 de Octubre. Por un lado, porque la crítica al exceso de lo militar y la simultánea reivindicación de la violencia en articulación con lo "popular" y las "masas" bien se entrelazaba con las enunciaciones que ya hacía una década venían planteando todas las disidencias. Más aún, Walsh había también reclamado hacía dos años el abandono de la "ofensiva" y de la "guerra", había reconocido la "derrota militar", y había incentivado la declaración de una "tregua" y de la "paz", por lo menos hasta que estuvieran dadas las condiciones para "volver a apostar al poder". Tampoco era original la demanda de alianzas políticas, que había sido enunciada de forma explícita por la Juventud Peronista Lealtad en tiempos del tercer peronismo (cuando no por la propia Conducción Nacional en varias de sus muchas intervenciones, o en sus fallidos intentos de participación en frentes o de conformación de partidos legales) ${ }^{33}$. Más allá de las particularidades que esta disidencia asumió en los albores de los años ochenta, en momentos de un deslizamiento de los lenguajes políticos y del inicio de la transición en Argentina, el recorrido efectuado hasta aquí permite insertar sus argumentos en disyuntivas ya transitadas en las aguas montoneras, por lo menos en las de sus voces disidentes. Buena parte de las discusiones y los esquemas de Montoneros 17 de Octubre venían enunciándose desde tiempo atrás, a pesar de la falta de reconocimiento y la rigidez de la cúpula oficial. Sobre todo, las representaciones ligadas al problema de la violencia, articuladas en torno a la difícil e inevitable pretensión de contar con la presencia de uno de los sujetos más insustanciales de la modernidad política, en general, y del peronismo, en particular, el "pueblo" (Lefort, 1994; Rosanvallon, 2002; Sigal y Verón, 2004). ${ }^{34}$

\section{Reflexiones finales}

En las páginas precedentes, examiné los documentos y publicaciones de distintos grupos disidentes que Montoneros tuvo a lo largo de su derrotero. Más que exponer con exhaustividad la conformación y la dinámica de dichos espacios, me interesó delimitar las discusiones, las representaciones y los horizontes que acompañaron su decisión por la violencia como práctica de intervención en la coyuntura. Es decir, busqué problematizar la violencia, no tanto como un instrumento o medio

integral"). Dejo este punto para futuras indagaciones. Al respecto, y sobre el vínculo entre Montoneros y el Frente Sandinista de Liberación Nacional, véase el artículo ya citado de Eudald Cortina Orero (2017).

33 Podría citarse la participación de la Juventud Peronista en el Frente Justicialista de Liberación en 1972, la experiencia del Partido Auténtico y del Movimiento Peronista Auténtico en 1975, y la creación del Movimiento Peronista Montonero en 1977 con su Secretaría de Relaciones Exteriores (Gillespie, 1987).

34 Valga mencionar que en sus diversas declaraciones y publicaciones Montoneros se orientó a concebir el pueblo como un sujeto homogéneo, y pasible de ser encarnado sin mediaciones por la organización, por lo menos hasta 1976 (Slipak, 2015). 


\section{Daniela Slipak}

escindible respecto de las proyecciones e imaginarios, sino como una práctica intrínseca de la identidad, las representaciones y los símbolos insurgentes.

Al respecto, cada una de las disidencias tuvo su especificidad, vinculada con sus características así como con la situación que atravesaba la política nacional y la experiencia exiliar. Desde 1972 a 1974, la Columna José Sabino Navarro impugnó la violencia "foquista" y "militarista" de la Conducción Nacional, y reclamó su articulación con los sectores "populares" y no con otros actores políticos del Movimiento Peronista. No cuestionó su despliegue en el marco de los gobiernos constitucionales que siguieron a la autodenominada Revolución Argentina, como sí lo hizo la Juventud Peronista Lealtad entre 1973 y 1974. Esta última adujo que, ejercida en dicho marco, la violencia se transformaba en "foquista". Desde su perspectiva, había sido legítima sólo durante los gobiernos de facto y gracias al acompañamiento "popular". Hacia mediados y fines de 1976, sin separarse de la organización, Walsh declaró que frente a la intensidad represiva de la dictadura era menester abandonar la guerra, y que era preciso articular la violencia montonera con lo "popular" y la política, aunque dejando la puerta abierta para volver a declarar la ofensiva. A principios de 1979, el Peronismo Montonero Auténtico acusó a la entonces exiliada Conducción Nacional de "militarista", "foquista", "vanguardista", y adujo que la "legítima" violencia "resistente" debía articularse con la estructuración de las "masas" y que podía rescatarse el auténtico montonerismo. En 1980, la última disidencia, Montoneros 17 de octubre, insistió en el abandono de la "guerra" en el contexto de la experiencia exiliar y advirtió sobre la gran cantidad de pérdidas que había implicado la Contraofensiva. Además, planteó que urgía desarrollar alianzas con otros sectores políticos para acompañar la "rebeldía popular", que no estaba exenta de una violencia cuya contrafigura era la violencia "militarista" de la Conducción Nacional.

Ahora bien, a pesar de sus particularidades, todas las disidencias articularon símbolos que bien trazan una continuidad. En primer lugar, su impugnación al exceso de la violencia, de lo militar y de lo bélico (encarnado casi siempre en la Conducción Nacional, tildada de "militarista", "vanguardista" y/o "aparatista") ${ }^{35}$. En segundo lugar, su demanda por desplegar actividades que se catalogaban de políticas, ligadas al trabajo territorial y fabril, o a las alianzas con otros actores de la coyuntura. En tercer lugar, más allá de los epítetos profesados a la cúpula montonera, ninguna desestimó la violencia como práctica, patentando el estatus decisivo que tenía para la militancia insurgente, no sólo como un medio para obtener objetivos a corto o mediano plazo, sino también como un horizonte de sentido que articulaba las coordenadas identitarias. Incluso, por momentos, y más allá de las críticas, algunas disidencias recurrieron a categorías ligadas a la

\footnotetext{
${ }^{35}$ No es tema de este artículo, pero una de las figuras interpretativas más comunes de las disidencias montoneras fue la idea de que habría existido un quiebre radical entre la voluntad de la Conducción Nacional, a la que se asignaba casi exclusiva responsabilidad de los errores cometidos, y el resto de los militantes, con poca gravitación en ellos. Esta figura del "quiebre" se superpuso con la del "desvío" respecto de los valores originarios, y la del "espejo" de las lógicas "enemigas” (Slipak, 2017).
} 


\section{Armas revolucionarias. Discusiones sobre la violencia en los grupos disidentes de Montoneros en los años setenta}

gramática bélica. En cuarto lugar, todas pensaron la figura de lo "popular" como instancia central para dirimir el signo "revolucionario" de su violencia y contraponerlo a la violencia de la cúpula montonera. Es decir, evocaron lo "popular" como principio de identificación y legitimación, y lo "foquista" o "militarista" como principio de diferenciación y deslegitimación. Considero que esta insistente repetición en situaciones radicalmente distintas, más que solicitarnos una sanción en torno a su carácter de verdad o falsedad, nos señala las disyuntivas constitutivas e irresolubles de la identidad montonera -o insurgente- en la Argentina de los setenta. Como advierte Elías Palti (2010, a y b) retomando algunas reflexiones de Alain Badiou (2005), la distinción entre violencia revolucionaria legítima y violencia ilegítima resulta indecidible (porque por detrás de ella asoma la cuestión de quién puede determinarlo, que involucra núcleos problemáticos del siglo $\mathrm{XX}$ como el de la Historia y el Sujeto, indisociables e incompatibles) y, sin embargo, fue estructurante de la subjetividad militante. Además, tal como lo mostré a lo largo del artículo, esta distinción puso en juego una de las aporías centrales de la modernidad política en general, articulada a partir de la necesaria apelación al "pueblo", un sujeto insustancial y, por lo tanto, siempre disputable. Desde luego, advertir esta disputa y este dispositivo de legitimación simbólico de la violencia no exime ni desestima el análisis respecto del conjunto de actores y sectores con el que cada disidencia tuvo vinculación en la coyuntura, y que la llevó a sostener que (ella sí) tenía vínculos con "lo popular". 36

Por otra parte, si bien no es objeto de las presentes páginas, quisiera mencionar que el análisis de los documentos oficiales de Montoneros no va en caminos tan divergentes de los trazados por las disidencias. A pesar de haber ignorado, cohibido, negado o reprimido a los grupos críticos, lo cierto es que muchas declaraciones de la Conducción Nacional reprodujeron sus esquemas. Aseveraban que ejercían la "violencia" asociada al "pueblo", se autocriticaban por haber cometido errores "militaristas" en el pasado, y reclamaban la necesidad de desplegar alianzas con otros sectores y de desarrollar trabajo territorial o en fábricas. ${ }^{37}$ Ello evidencia que "lo popular" era un símbolo extensamente disputado en las tramas insurgentes, y un elemento decisivo para medir el carácter "legítimo" de la propia violencia (al tiempo que lo "militarista" o "foquista" era un símbolo de diferenciación, por lo menos durante la década en cuestión).

Para terminar por donde empecé, creo que el recorrido efectuado permite identificar un punto en relación a la bibliografía académica más clásica sobre la insurgencia de los años setenta, en general, y sobre Montoneros, en particular.

\footnotetext{
36 Por ejemplo, sobre los vínculos de Montoneros Sabino Navarro con barrios y fábricas en la ciudad de Córdoba y el Gran Rosario, puede verse Seminara (2015). Corriendo el foco a Montoneros, sobre sus vínculos con trabajadores navales en Zona Norte a través de la Juventud Trabajadora Peronista, puede verse Federico Lorenz (2007), y sobre sus vínculos con barrios periféricos de La Plata a través de la Juventud Peronista local, puede verse el trabajo de Horacio Robles (2014).

37 Puede verse como ejemplo el Boletín Interno n. 4 (Informe del Consejo Nacional del Partido Montonero) de sept. de 1977. Dejo esta línea de trabajo (la apropiación que la Conducción Nacional hizo de las críticas disidentes) para futuras indagaciones.
} 


\section{Daniela Slipak}

Como señalé en la introducción, las interpretaciones suelen identificar un momento de despliegue de una violencia más o menos legítima, o política, o aceptada, o esperable habida cuenta de la historia del país; y otro momento de militarización, de exceso de lo militar por sobre lo político, y de aislamiento respecto de los sectores populares. En breve, la figura interpretativa de la "violencia popular" que se desplaza a la de, para usar los términos de Walsh, la "patrulla perdida". ${ }^{38}$ Como se ha visto, estos argumentos se sitúan en la estela de los señalamientos disidentes, es decir, en las claves de lectura nativas que los propios actores dieron a la experiencia que se busca analizar. Se continúa, así, de algún modo, dentro de los contornos de aquello que fue decible (y aquello que no) para los protagonistas. Sin desconocer el efecto ordenador de dichas categorías, ${ }^{39}$ quizás convenga, a más de cuarenta años, precisar de dónde provienen y en qué marcos de inteligibilidad se gestaron.

\section{Bibliografía}

Aboy Carlés, G. (2001). Las dos fronteras de la democracia argentina. La reformulación de las identidades políticas de Alfonsín a Menem. Rosario: Homosapiens.

Aha, 0. (2006). La nación futura. Rodolfo Puiggrós en las encrucijadas argentinas del siglo XX. Buenos Aires: Eudeba.

Anguita, E. y Caparrós, M. (2006). La Voluntad. Una historia de la militancia revolucionaria en la Argentina. Buenos Aires: Planeta, 2006

Anzorena, 0. (1998). Tiempo de violencia y utopía. Del golpe de Onganía (1966) al golpe de Videla (1976). Buenos Aires: Pensamiento Nacional.

Badiou, A. (2005). El siglo. Buenos Aires: Manantial.

\footnotetext{
38 Los Papeles de Walsh, Cuadernos del Peronismo Montonero Auténtico, oct. 1979, p. 13.

${ }^{39}$ Es cierto que esta dicotomía cronológica puede orientar al analista en relación al trabajo barrial, universitario, estudiantil y fabril, así como a la cantidad y la envergadura de los hechos armados desplegados en las diversas coyunturas. Sin embargo, no menos cierto es que tiende a ocultar los esquemas y símbolos militares que atravesaron los primeros cinco años de la organización (Slipak, 2015), o las apuestas políticas y alianzas efectuadas durante el exilio (Acha, 2006; Bernetti y Giardinelli, 2014; Robledo, 2018; Confino, 2018 y 2019b), por mencionar dos ejemplos. Es decir, considero que dicha dicotomía cronológica, cuyo origen se remonta a las discusiones nativas, desdibuja una hibridación de prácticas y concepciones que, aunque tensa y cambiante, fue intrínseca a la identidad montonera.
} 


\section{Armas revolucionarias. Discusiones sobre la violencia en los grupos disidentes de Montoneros en los años setenta}

Bernetti, J. Y Giardinelli, M. (2014). México: el exilio que hemos vivido. Memoria del exilio argentino en México durante la dictadura 1976-1983. Buenos Aires: Octubre.

Bonasso, M. (2000). Diario de un clandestino. Buenos Aires: Planeta.

Caballero, R. y Larraquy, M. (2000). Galimberti: de Perón a Susana, de Montoneros a la CIA. Buenos Aires: Norma.

Calveiro, P. (2005). Política y/o violencia. Una aproximación a la guerrilla de los años 70. Buenos Aires: Norma.

Carnovale, V. (2007). Aportes y problemas de los testimonios en la reconstrucción del pasado reciente en la Argentina. En Franco, M. y Levín, F. (comps.). Historia reciente. Perspectivas y desafíos para un campo en construcción. Buenos Aires: Paidós.

Confino, H. E. (2018). La Contraofensiva Estratégica de Montoneros. Entre el exilio y la militancia revolucionaria (1976-1980) (Tesis de doctorado inédita). UNSAM, Buenos Aires.

Confino, H. E. (2019a). Exilio, debate y ruptura. Los balances de la Contraofensiva montonera de 1979 y la constitución de "Montoneros 17 de octubre". Anuario (31). Recuperado https://anuariodehistoria.unr.edu.ar/index.php/Anuario/article/view/273

Confino, H. E. (2019b). El reclutamiento y entrenamiento para la Contraofensiva (1978-1980). Reflexiones sobre la política y la violencia en los últimos años de Montoneros. Folia Histórica del Nordeste (36). Recuperado de https://revistas.unne.edu.ar/index.php/fhn/article/view/4047/3682

Cortina Orero, E. (2017). Internacionalismo y revolución sandinista: proyecciones militantes y reformulaciones orgánicas en la izquierda revolucionaria argentina. EIAL (28). Recuperado de http://eial.tau.ac.il/index.php/eial/article/view/1521

Duzdevich, A., Raffoul, N. y Beltramini, R. (2015). La lealtad. Los Montoneros que se quedaron con Perón. Buenos Aires: Sudamericana.

El Kadri, E. y Rulli, J. (1984). Diálogos en el exilio. Buenos Aires: Foro Sur.

Esquivada, Gabriela (2009). Noticias de los Montoneros. La historia del diario que no pudo anunciar la revolución. Buenos Aires: Sudamericana.

Franco, M. (2008). El exilio. Argentinos en Francia durante la dictadura. Buenos Aires: Siglo XXI. 


\section{Daniela Slipak}

Franco, M. (2012). Un enemigo para la Nación. Orden interno, violencia y subversión, 1973-1976. Buenos Aires: Fondo de Cultura Económica.

Franco, M. (2015). La teoría de los dos demonios en la primera etapa de la posdictadura. En Feld, C. y Franco, M. (dirs.). Democracia, hora cero. Actores, políticas y debates en los inicios de la posdictadura. Buenos Aires: Fondo de Cultura Económica.

Gago, V. (2012). Controversia: una lengua del exilio. Buenos Aires: Biblioteca Nacional.

Gillespie, R. (1987). Soldados de Perón. Los Montoneros. Buenos Aires: Grijalbo.

Grassi, R. (2015). Periodismo sin aliento. El descamisado: la revista que cubrió el conflicto y la ruptura de Perón con Montoneros. Buenos Aires: Sudamericana.

Inchauspe, L. y Noguera, A. (2011). La Columna José Sabino Navarro: un acercamiento a la militancia armada peronista en la córdoba de los '70 a través de fuentes orales. Ponencia presentada en el I Workshop Interuniversitario "Partidos políticos y elecciones en espacios regionales y provinciales”, Resistencia.

Inchauspe, L. y Noguera, A. (2015). 'Ya éramos en origen algo distinto'. La Columna Sabino Navarro y su desarrollo en la Córdoba de los '70. Estudios (34). Recuperado de https://revistas.unc.edu.ar/index.php/restudios/article/view/13334

Jensen, S. (2007). La provincia flotante. El exilio argentino en Cataluña (1976-2006). Barcelona: Fundació Casa América Catalunya.

Jensen, S. (2010). Los exiliados. La lucha por los derechos humanos durante la dictadura. Buenos Aires: Sudamericana.

Jensen, S. y Lastra, M. S. (eds.). Exilios: Militancia y represión. Nuevas fuentes y nuevos abordajes de los destierros de la Argentina de los años setenta. La Plata: EDULP.

Lefort, C. (1994). L'invention démocratique. Les limites de la domination totalitaire. París: Fayard.

Lenci, L. (2008). Justicia, política y violencia. Un análisis de los cuerpos normativos montoneros 1972-1975. Ponencia presentada en las II Jornadas de Partidos Armados en la Argentina de los Setenta, UNSAM, Buenos Aires, Argentina.

Montero, A. S. (2008). Héroes, ortodoxos, disidentes o traidores. Los avatares de la Juventud Peronista Lealtad (1973-1976). V Jornadas de Sociología de la UNLP,

La Plata, Argentina. Recuperado de http://www.memoria.fahce.unlp.edu.ar/trab_eventos/ev.6265/ev.6265.pdf 


\section{Armas revolucionarias. Discusiones sobre la violencia en los grupos disidentes de Montoneros en los años setenta}

Moyano, M. J. (1995). Argentina's Lost Patrol. Armed Struggle, 1969-1979. Connecticut:Yale University Press.

Ollier, M. M. (1998). La creencia y la pasión. Privado, público y político en la izquierda revolucionaria. Buenos Aires: Ariel.

Palti, E. J. (2010a). La crítica de la razón militante. Una reflexión con motivo de la fidelidad del olvido de Blas de Santos y el 'affaire del Barco'. En García, L. (comp.). No matar. Sobre la responsabilidad. Segunda compilación de intervenciones. Córdoba: Universidad Nacional de Córdoba.

Palti, E. J. (2010b). La violencia revolucionaria como problema histórico-conceptual. Notas para una arqueología de la subjetividad militante. En García, L. (comp.). No matar. Sobre la responsabilidad. Segunda compilación de intervenciones. Córdoba: Universidad Nacional de Córdoba.

Peyrou, A. (2010). Lealtad. Lucha Armada en la Argentina (Anuario).

Portelli, (1991). Lo que hace diferente a la Historia Oral. En Schwarztein, D. (comp.). La Historia Oral. Buenos Aires: CEAL.

Portelli (2017). El uso de la entrevista en la historia oral. Anuario (20). Recuperado de https://anuariodehistoria.unr.edu.ar/index.php/Anuario/article/view/205

Pozzoni, M. (2017). Leales. De la Tendencia Revolucionaria a la Juventud Peronista Lealtad. Buenos Aires: Imago Mundi.

Robles, H. (2014). La retaguardia revolucionaria. Una descripción de la estructura de unidades básicas controlada por la juventud peronista y Montoneros en los barrios populares de la ciudad de La Plata (1972-1974). En Tortti, M. C. (dir.) y Chama, M. y Celentano, A. (co-dirs). La nueva izquierda argentina (1955-1976). Socialismo, peronismo y revolución. Rosario: Prohistoria ediciones.

Rodeiro, L. (1996). Fantasías de bandoneón (una disidencia montonera). Buenos Aires: Ediciones de la Cortada.

Rodeiro, L. (2006). El 'Documento Verde': la primera crítica a Montoneros desde Montoneros. Lucha Armada en la Argentina (6).

Rodeiro, L. Textos Viscerales. Buenos Aires: Caterva.

Robledo, P. (2018). Montoneros y Palestina. De la revolución a la dictadura. Buenos Aires: Planeta.

Rosanvallon, P. (2002). Le peuple introuvable. Paris: Gallimard. 


\section{Daniela Slipak}

Sadi, M. (2009). El caso Lanuscou. Columna Norte, la otra historia. Buenos Aires: Nuevos Tiempos.

Salcedo, J (2011). Los montoneros del barrio. Buenos Aires: Eduntref.

Seminara, L. (2015). Bajo la sombra del ombú. Montoneros Sabino Navarro, historia de una disidencia. Buenos Aires: Imago Mundi.

Sigal, S. y Verón, E. (2004). Perón o muerte. Los fundamentos discursivos del fenómeno peronista. Buenos Aires: Eudeba.

Slipak, D. (2015). Las revistas montoneras. Cómo la organización construyó su identidad a través de sus publicaciones. Buenos Aires: Siglo XXI.

Slipak, D. (2017). Sobre desvíos, espejos y cúpulas. Las disidencias montoneras y las lecturas sobre los años setenta. Izquierdas (32). Recuperado de http://www.izquierdas.cl/images/html/n32/index32.html

Slipak, D. (2018). Comunicar la disidencia. Un recorrido por tres escisiones de Montoneros en los setentas. Izquierdas (41). Recuperado de http://izquierdas.cl/images/html/n41/index41.html

Slipak, D. (2019). Instrumento y lazo. Sobre la violencia en Hannah Arendt. Anacronismo $e$ irrupción (17). Recuperado de https://publicaciones.sociales.uba.ar/index.php/anacronismo/article/view/4518

Svampa, M. (2003). El populismo imposible y sus actores, 1973-1976. En James, Daniel (dir.). Violencia, proscripción y autoritarismo (1955-1976). Buenos Aires: Sudamericana.

Yankelevich, P. (2010). Ráfagas de un exilio. Argentinos en México, 1974-1983. Buenos Aires: Fondo de Cultura Económica.

\section{Documentos y publicaciones citados}

Documento Verde, Columna Sabino Navarro, julio de 1972, en Lucha Armada en la Argentina (6).

Disposiciones sobre la Justicia Penal Revolucionaria, 1972. Comisión Provincial por la Memoria, situada en La Plata, Buenos Aires, Archivo DIPBA, Mesa D (s), Carpeta Varios, Legajo número 581, 16 folios. -Militancia peronista para la liberación, número 32, 24/01/74, Buenos Aires. Disponible en Centro de Documentación e Investigación de la Cultura de Izquierdas en Argentina (Cedinci), Buenos Aires.-Puro 


\section{Armas revolucionarias. Discusiones sobre la violencia en los grupos disidentes de Montoneros en los años setenta}

Pueblo Venceremos, número 4, 2da quincena de agosto de 1974. Disponible en Cedinci, Buenos Aires.

El peronista lucha por la liberación, número 5, 21/05/74. Disponible en Cedinci, Buenos Aires.

Movimiento para la Liberación y Reconstrucción Nacional, número 2, 2da quincena de mayo de 1974; número 6, 2da quincena de julio de 1974; número 8, 2 da quincena de agosto de 1974; número 10, 2 da quincena de septiembre de 1974. Disponibles en Cedinci, Buenos Aires.

Respuesta de Montoneros de Moreno al Mamotreto, febrero/marzo de 1974, en Salcedo, J. (2011). Los montoneros del barrio. Buenos Aires: Eduntref.

Evita Montonera, número 5, junio-julio de 1975; número 8, octubre de 1975; número 12, febrero-marzo de 1976; número 14, octubre de 1976; número 21, abril-mayo de 1978. Disponibles en Cedinci, Buenos Aires.

El Montonero, número 11, Conducción Nacional de Montoneros, 24/04/76. Disponible en www.eltopoblindado.com

Lettre ouverte d'un écrivain à la Junte militaire d'Argentine, Mouvement Peroniste Montonero, sin fecha. Disponible en Bibliothèque de Documentation Internationale Contemporaine (BDIC), Nanterre.

Boletín Interno Número 4 (Informe del Consejo Nacional del Partido Montonero), septiembre de 1977. Disponible en www.eltopoblindado.com

Los Papeles de Walsh, Cuadernos del Peronismo Montonero Auténtico, octubre de 1979. Los escritos de Walsh tiene fechas de 27/08/76, 23/11/76, 02/01/77 y 05/01/77. Disponible en BDIC, Nanterre.

Sobre la deserción de cinco militantes del Partido y cuatro milicianos en el exterior, Resolución número 045/79 del Partido Montonero, 1979. Disponible en BDIC, Nanterre.

Reflexiones para la construcción de una alternativa peronista montonera auténtica, Peronismo Montonero Auténtico, junio de 1979. Disponible en BDIC, Nanterre. Controversia para el examen de la realidad argentina, número 1, octubre de 1979. Disponible en Cedinci, Buenos Aires.

Ante la crisis del Partido. Reflexiones críticas y una propuesta de superación, Boletín Interno número 13 del Partido Montonero, febrero de 1980. Disponible en BDIC, Nanterre. 


\section{Daniela Slipak}

Boletín Interno número 13 del Partido Montonero, febrero de 1980. Disponible en BDIC, Nanterre.

Sin título, Montoneros 17 de octubre, abril de 1980. Disponible en www.eltopoblindado.com

\section{Entrevistas utilizadas}

Entrevista a Marcela Durrieu realizada por la autora en Provincia de Buenos Aires, 19/5/2011.

Entrevista a Alejandro Peyrou realizada por la autora en la Ciudad de Buenos Aires, 2/6/2011 y 15/7/2011.

Cuestionario realizado por la autora por mail a Luis Rodeiro, 8/6/2011.

Entrevista a Miguel Saiegh, realizada por la autora en la Ciudad de Buenos Aires, $29 / 8 / 2011$.

Entrevista a Ignacio Vélez realizada por la autora en la Ciudad de Buenos Aires, $24 / 11 / 2011$.

Entrevista a Dante Oberlin realizada por la autora en la Ciudad de Buenos Aires, $19 / 4 / 2012$.

Entrevista a Marcelo Langieri realizada por la autora en la Ciudad de Buenos Aires, $13 / 10 / 2016$.

Entrevista a Miguel Fernández Long realizada por la autora en Provincia de Buenos Aires, 1/11/2016.

Entrevista a "Yuyo" realizada por la autora en la Ciudad de Buenos Aires, $22 / 11 / 2016$.

Recibido: $11 / 07 / 2020$

Evaluado: $14 / 08 / 2020$

Versión Final: 08/11/2020 